\title{
Associations of sustained smoking and smoking cessation with work-related outcomes: a longitudinal analysis
}

\author{
Sigrid A. Troelstra ${ }^{1,2}$. Cécile R. L. Boot ${ }^{1}$ (D) Janneke Harting ${ }^{2} \cdot$ Goedele A. Geuskens $^{3}$ - Anton E. Kunst ${ }^{2}$. \\ Allard J. van der Beek ${ }^{1}$
}

Received: 13 May 2019 / Accepted: 20 October 2020 / Published online: 10 November 2020

(c) The Author(s) 2020

\begin{abstract}
Purpose The aim of this study was to assess the association between sustained smoking and quitting with work-related outcomes among older workers.

Methods We categorized a sample of older employees into non-smokers, sustained smokers and quitters. Multivariable regression models were used to test longitudinal associations of sustained smoking and smoking cessation with sickness absence, productivity loss and work ability.

Results We included 3612 non-smokers, 673 sustained smokers and 246 quitters. Comparing sustained smokers to nonsmokers, we found higher (but not statistically significant) sickness absence for sustained smokers $[1.01,95 \%$ confidence interval (CI) $-0.16-2.17]$. We did not find differences in productivity loss (OR $0.82,95 \%$ CI $0.60-1.13$ ) and work ability $(0.05,95 \% \mathrm{CI}-0.05-0.15)$. For employees with a relatively high physical health at baseline, comparing quitters to sustained smokers, we found higher (but not statistically significant) productivity loss for quitters (OR 2.23, 95\% CI 0.94-5.31), and no difference in sickness absence $(0.10,95 \%$ CI $-2.67-2.87)$, and work ability $(-0.10,95 \%$ CI $-0.36-0.16)$. For employees with a relatively low physical health at baseline, comparing quitters to sustained smokers, we found a statistically significant lower work ability $(-0.31,95 \% \mathrm{CI}-0.57-0.05)$, and no difference in sickness absence $(2.53,95 \% \mathrm{CI}-1.29-6.34)$ and productivity loss (OR 1.26, 95\% CI 0.66-2.39).

Conclusions We found no evidence that sustained smokers have less favorable work-related outcomes than non-smokers or that quitters have more favorable work-related outcomes than sustained smokers. The benefits of smoking cessation for employers might take a longer time to develop.
\end{abstract}

Keywords Smoking $\cdot$ Smoking cessation $\cdot$ Sickness absence $\cdot$ Work productivity $\cdot$ Work ability $\cdot$ Older workers

Cécile R. L. Boot

crl.boot@amsterdamumc.nl

1 Department of Public and Occupational Health, Amsterdam Public Health Research Institute, Amsterdam UMC, VU University, Van der Boechorstraat 7, 1081 BT Amsterdam, The Netherlands

2 Department of Public Health, Amsterdam Public Health Research Institute, Amsterdam UMC, University of Amsterdam, Amsterdam, The Netherlands

3 Netherlands Organisation for Applied Scientific Research TNO, Leiden, The Netherlands

\section{Background}

Smoking remains a major worldwide public health threat (World Health Organization 2018). Next to an increased risk of premature death, smokers experience more health problems compared to non-smokers. Smokers have an increased risk of developing cardiovascular diseases, chronic obstructive pulmonary disease (COPD), and various types of cancer (Kõks et al. 2018; Taghizadeh et al. 2016). Furthermore, smoking is associated with a lower quality of life (Coste et al. 2014; Goldenberg et al. 2014) and mental health problems such as depression and anxiety (Fluharty et al. 2016; Prochaska et al. 2017). The negative health impact of smoking becomes more prominent with older age (Nicita-Mauro et al. 2008; Østbye and Taylor 2004). 
Through its negative influence on physical health, mental health and quality of life, smoking can influence employability of workers. Employability can be captured by different work-related outcomes, such as sickness absence, work productivity and work ability (Tarro et al. 2020). According to two systematic reviews, smoking is associated with an increase in sickness absence rates (Troelstra et al. 2020; Weng et al. 2013). Smoking is also associated with a decrease in work productivity (Berman et al. 2014; Bunn et al. 2006; Halpern et al. 2001; Sherman and Lynch 2013). Most studies found negative associations between smoking and work ability [i.e., self-assessed work ability in relation to an individual's resources and job demands (Van den Berg et al. 2009)] (Airila et al. 2012; Augusto et al. 2015; Mohammadi et al. 2014; Tuomi et al. 1991), while one study did not find an association (Fischer and Martinez 2013). Furthermore, smoking is associated with a risk of early exit from work (Bengtsson and Nilsson 2018; Husemoen et al. 2004). Few studies have compared the association between smoking and different work-related outcomes (Berman et al. 2014; Bunn et al. 2006; Halpern et al. 2001; Sherman and Lynch 2013; Tsai et al. 2005), and to our knowledge, no study has included sickness absence, work productivity, and work ability.

The workplace is a setting that has the potential to reach large groups of people, to have higher intervention participation rates compared to non-occupational settings, and to encourage peer-support and positive peer-pressure (Cahill and Lancaster 2014). A Cochrane review on the effect of workplace smoking cessation interventions found strong evidence for the effectiveness of workplace based smoking cessation interventions (Cahill and Lancaster 2014). More knowledge about the relation between smoking cessation and work-related outcomes, especially among older workers, could support the further development and implementation of smoking cessation interventions in the workplace.

Improving the health status of older workers through encouraging smoking cessation (Sachs-Ericsson et al. 2009), could improve their work-related outcomes and sustained employability, thereby increasing the probability they will be able to work up till retirement age (Nicita-Mauro et al. 2008). Several studies have found that smoking cessation reduces the risk of all-cause mortality (Doll et al. 1994; Kenfield et al. 2008). For those who quit smoking early in their adult life, mortality decreased to the level of a never smoker (Doll et al. 1994; Kenfield et al. 2008). Smokers who quit after the age of 45 year experienced an increase in survival compared to sustained smokers (Doll et al. 1994). In several studies attempting to determine the effect of smoking status, a distinction is made between non-smokers, current smokers, and former smokers (Bunn et al. 2006; Suwa et al. 2017; Wacker et al. 2013). However, since former smokers could have been abstinent for several decades, this category does not necessarily reflect the effects of smoking cessation.

Few studies have looked into the effect of smoking cessation on work-related outcomes. One study found that within 0-4 years after smoking cessation, absence and productivity loss decreased (Baker et al. 2017). According to another study, after cessation, objective measures of productivity decreased in the first years, but exceeded the productivity of sustained smokers 1-4 years after cessation (Halpern et al. 2001). Therefore, more research on the association between smoking cessation and work-related outcomes is needed.

Therefore, the aims of this study are to assess (1) the effect of sustained smoking, and (2) the effect of quitting on sickness absence, productivity loss and work ability among older workers. We hypothesize that comparing sustained smoking to non-smoking, sustained smoking is associated with higher levels of sickness absence and productivity loss, and a lower level of work ability, and that comparing quitting to sustained smoking, quitting is associated with lower levels of sickness absence and productivity loss, and a higher level of work ability.

\section{Methods}

\section{Study design and participants}

This study used data from the Study on Transitions in Employment, Ability and Motivation in the Netherlands (STREAM) (Ybema et al. 2014). This is a prospective

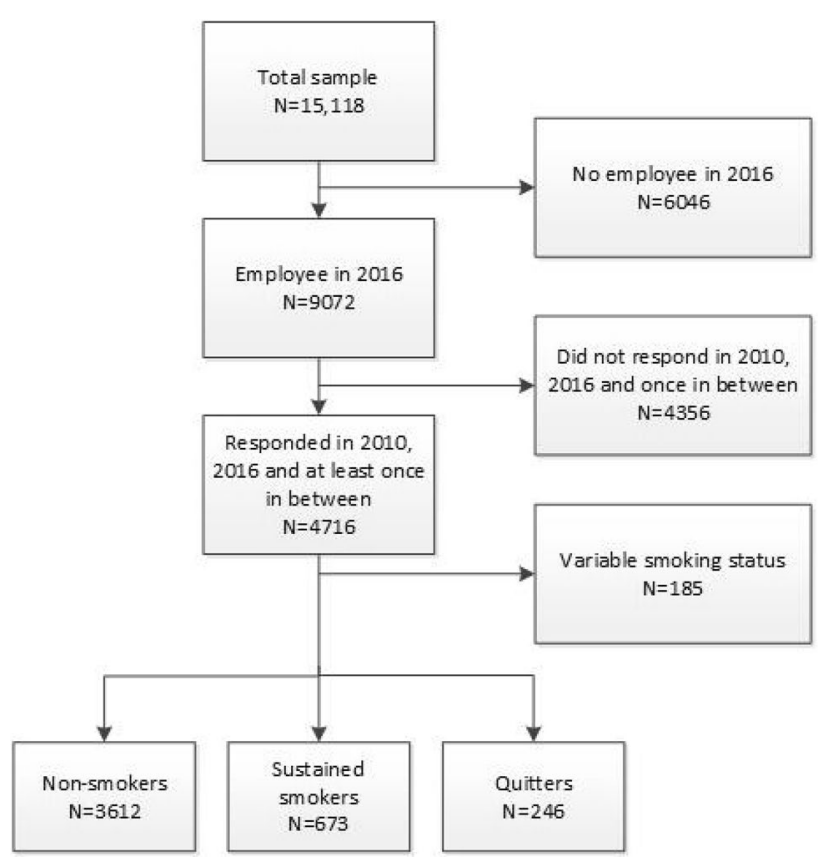

Fig. 1 Flow chart of participant inclusion 
cohort study consisting of a total sample of 15,118 Dutch persons aged 45-64 years (Ybema et al. 2014) (Fig. 1). The STREAM cohort was set up to provide insight in factors that influence working until retirement in a healthy and productive manner (Ybema et al. 2014). STREAM participants completed online questionnaires in 2010, 2011, 2012, 2013, 2015 and 2016 on topics related to employment, work characteristics, health status, sickness absence, productivity loss, and work ability. For the present study, we excluded STREAM participants when they were not employed in 2016 (T6) $(N=6046)$, when they did not participate in the questionnaire in 2010 (T1), 2016 (T6), and at least once in between $(20112012,2013,2015$ (T2-T5) $(N=4356)$, and when their smoking status could not be categorized into nonsmoker, sustained smoker or quitter, due to frequent changes in their smoking status $(N=185)$. The analytic sample consisted of 4531 individuals (Fig. 1).

Comparisons between respondents who participated in all questionnaires versus those who missed one or more followup questionnaire showed some selective loss to follow-up. Due to the large sample size, differences were statistically significant but very small. For all variables, Cohen's $d$ was smaller than 0.201, except for age (0.218), indicating that selective follow-up will not seriously have biased the results (van den Heuvel et al. 2016).

\section{Measures}

\section{Outcomes}

Individual sickness absence percentage was calculated by dividing the self-reported days on sick leave in the past 12 months by the number of potential working day (i.e., corrected for part-time work and with full-time work defined as 215 working days per year). This represents the proportion of worktime missed due to illness in the past year. We also dichotomized sickness absence percentage into any sickness absence ("yes" or "no") to make our findings comparable with recent systematic reviews on smoking and sickness absence.

Productivity loss at work was assessed in all surveys using a question on the self-assessed quantity of executed work in the last 4 weeks compared to usual (Ybema et al. 2014). Answers were categorized in $1=$ "less compared to normal", $2=$ "similar to normal", and 3="more compared to normal". We dichotomized the answers into $0=$ "no productivity loss, i.e., similar or higher productivity compared to normal" and $1=$ "productivity loss, i.e., lower productivity compared to normal".

Work ability in relation to job demands was assessed at all survey waves using the second dimension of the work ability index (WAI 2) (Ilmarinen 2007, 2009; Tuomi et al.
2007). The Work Ability Index (WAI), used to assess work ability, has been widely researched and is considered to have high predictive validity and cross-national stability (Lundin et al. 2017; Radkiewicz and Widerszal-Bazyl 2005). The WAI 2 consists of two questions that subjectively assess current work ability in relation to the (a) physical and (b) mental demands of their job on a scale from $1=$ "very poor" to $5=$ "very good". The scores were combined into dimension 2 of the work ability index, work ability in relation to job demands, ranging from $2=$ "very bad" to $10=$ "excellent" (van den Heuvel et al. 2016). Previous research has shown that the WAI 2 is strongly associated with both the overall WAI and other constructs that are related to work ability (Ebener et al. 2019). In contrast to the outcome variables sickness absence percentage and productivity loss, where increases can be regarded as 'negative', an increase in work ability can be regarded as 'positive'.

\section{Smoking status}

Smoking status was assessed at all survey waves by the question whether participants were a current smoker, former smoker, or non-smoker. Participants were divided in three categories based on their smoking status. The first category consisted of non-smokers, those who reported not to smoke at all completed surveys. The second category consisted of sustained smokers. These smokers reported to smoke during at least $75 \%$ of all completed surveys (meaning that depending on their participation rate, they could report being a former smoker once). The third category, 'quitters' consisted of people who reported being a current smoker at $\mathrm{T} 1$ and reported being a former smoker in their last two completed surveys.

\section{Potential confounders}

We included the following baseline variables as potential confounders: age, gender, educational level, physical health, mental health, BMI, and job demands. Age was measured on a continuous scale and gender was measured dichotomously. Educational level was divided in three groups (low, middle, high), based on the highest reported education type. Physical health was measured using the SF12 physical composite scale score (Ware et al. 1996). Mental health was measured using the SF12 mental composite scale score (Ware et al. 1996). Body Mass Index (BMI) was determined through self-reported body weight and height of participants and dichotomized into $\leq 25$ and $>25$ to distinguish between under/normal bodyweight and overweight participants. Job demands was measured using four questions on whether the participant had to work very fast, extra hard, do a lot of work, or had to do hectic work (four items, Cronbach's $\alpha=0.87$ ) (van den Heuvel et al. 2016). 


\section{Statistical analysis}

First, all variables were analyzed descriptively to report baseline characteristics of non-smokers, sustained smokers and quitters. Afterwards, the associations between smoking status (based on T1-T6) and sickness absence, productivity loss, and work ability (as reported at T6) were analyzed using logistic (for the outcome regarding productivity loss) and linear (for the outcomes regarding sickness absence and work ability) regression analyses. Even though work ability was an ordinal outcome measure, since in total 17 different scores were reported (from 2 to 10 with steps of 0.5 ), we used linear regression analyses. Six different regression analyses were performed, two for each of the three outcomes, one assessing the effects of sustained smoking with nonsmoking as reference group (aim 1) and one assessing the effects of quitting with sustained smoking as reference group (aim 2). Furthermore, since we expected physical health status to be of influence on the decision to quit smoking, we tested for interactions between smoking cessation and physical health at baseline. Comparing quitting versus sustained smoking, we found significant interactions between physical health and the outcomes. Therefore, we stratified our analysis based on the median physical health score (54.88) of the study population. For each analysis, we built four models: (0) univariate analyses, (1) with demographic variables (age, gender and educational level), (2) with demographic variables and job demands and (3) with demographic variables, job demands and health status (physical health, mental health and BMI). Since health status could be both a confounder and a mediator in the relation between smoking status and work-related outcomes, we added these variables to the final model. The analyses were performed using SPSS statistical software version 22 .

\section{Results}

\section{Sustained smoking versus non-smoking}

Baseline characteristics for sustained smokers $(N=673)$ and non-smokers $(N=3612)$ are shown in Table 1 . Table 2 shows the longitudinal effects of sustained smoking on sickness absence percentage, productivity loss, and work
Table 1 Characteristics of nonsmoking, sustained smoking and quitting participants at baseline

\begin{tabular}{|c|c|c|c|c|c|c|c|c|c|}
\hline & \multicolumn{3}{|c|}{ Non-smokers $(N=3612)$} & \multicolumn{3}{|c|}{$\begin{array}{l}\text { Sustained smokers } \\
(N=673)\end{array}$} & \multicolumn{3}{|c|}{ Quitters $(N=246)$} \\
\hline & Mean & SD & $\%$ & Mean & SD & $\%$ & Mean & SD & $\%$ \\
\hline Age & 52.21 & 4.64 & & 52.09 & 4.45 & & 52.24 & 4.41 & \\
\hline Male & & & 56.9 & & & 57.4 & & & 53.3 \\
\hline Low education & & & 23.4 & & & 35.2 & & & 29.3 \\
\hline Physical health & 52.31 & 7.25 & & 51.79 & 7.05 & & 51.71 & 6.92 & \\
\hline Mental health & 52.32 & 8.09 & & 51.99 & 8.09 & & 51.95 & 8.31 & \\
\hline $\mathrm{BMI}>25$ & & & 65.8 & & & 54.4 & & & 59.8 \\
\hline Job demands & 3.15 & 0.74 & & 3.25 & 0.73 & & 3.24 & 0.75 & \\
\hline Sickness absence $\%$ & 4.02 & 12.26 & & 4.53 & 12.25 & & 4.12 & 12.23 & \\
\hline Productivity loss & & & 7.2 & & & 7.8 & & & 3.0 \\
\hline Work ability & 8.26 & 1.13 & & 8.24 & 1.11 & & 8.20 & 1.11 & \\
\hline
\end{tabular}

$N$ number; $S D$ standard deviation; $B M I$ body mass index

Table 2 Longitudinal effects of sustained smoking on sickness absence, productivity loss, and work ability with non-smokers as reference group, $N=4285$

\begin{tabular}{|c|c|c|c|c|}
\hline & Univariate & Model 1 (+ demographics) & $\begin{array}{l}\text { Model } 2 \text { (+ demograph- } \\
\text { ics, job demands) }\end{array}$ & $\begin{array}{l}\text { Model } 3 \text { (+ demographics, } \\
\text { job demands and health } \\
\text { status) }\end{array}$ \\
\hline & Coef/OR $[95 \% \mathrm{CI}]$ & Coef/OR $[95 \% \mathrm{CI}]$ & Coef/OR $[95 \%$ CI] & Coef/OR $[95 \% \mathrm{CI}]$ \\
\hline Sickness absence $\%$ (Coef $)^{1}$ & $0.88[-0.28-2.03]$ & $0.80[-0.36-1.96]$ & $0.82[-0.35-2.00]$ & $1.01[-0.16-2.17]$ \\
\hline Productivity loss $(\mathrm{OR})^{2}$ & $0.81[0.60-1.10]$ & $0.83[0.61-1.12]$ & $0.85[0.62-1.15]$ & $0.82[0.60-1.13]$ \\
\hline Work ability (Coef) ${ }^{1}$ & $0.01[-0.09-0.11]$ & $0.02[-0.08-0.12]$ & $0.04[-0.06-0.14]$ & $0.05[-0.05-0.15]$ \\
\hline
\end{tabular}

OR odds ratio; Coef coefficient; $C I$ confidence interval

${ }^{1}$ Results based on linear regression modelling

${ }^{2}$ Results based on logistic regression modelling 
ability. Comparing sustained smokers to non-smokers, we found that sustained smokers had a somewhat higher (but not statistically significant) sickness absence percentage. After addition of health status in model 3, the association with sickness absence changed substantially compared to model 2 (OR $0.82,95 \% \mathrm{CI}-0.35-2.00, p 0.17$ vs. $1.01,95 \% \mathrm{CI}$ $-0.16-2.17, p 0.09$ ). We did not find statistically significant differences in productivity loss (OR $0.82,95 \%$ CI 0.60 $-1.13, p 0.23)$ and work ability $(0.05,95 \% \mathrm{CI}-.05-0.15, p$ 0.32 ) comparing sustained smokers to non-smokers.

\section{Quitting versus sustained smoking}

Baseline characteristics for quitters $(N=246)$ and sustained smokers $(N=673)$ are shown in Table 1 . Table 3 shows the longitudinal effects of smoking cessation on sickness absence, productivity loss and work ability, stratified for physical health score. For employees with a relatively high physical health score at baseline, comparing quitters to sustained smokers, we found substantially, but not statistically significant, higher odds of productivity loss for quitters (OR $2.23,95 \%$ CI $0.94-5.31, p 0.07)$. We did not find statistically significant differences in sickness absence percentage $(0.10$, $95 \% \mathrm{CI}-2.67-2.87, p 0.94)$, and work ability score $(-0.10$, 95\% CI -0.36-0.16, $p$ 0.43) (Table 3).

For employees with a relatively low physical health score at baseline, comparing quitters to sustained smokers, we found a statistically significant lower work ability score for quitters $(-0.31,95 \% \mathrm{CI}-0.57-0.05, p 0.02)$. We did not find statistically significant differences in sickness absence percentage $(2.53,95 \% \mathrm{CI}-1.29-6.34, p 0.19)$ and productivity loss (OR 1.26, 95\% CI 0.66-2.39, $p$ 0.48).

\section{Discussion}

\section{Summary of main findings}

In contrast to our hypotheses, we found no differences in sickness absence percentage, productivity loss and work ability score for sustained smokers compared to non-smokers, although sickness absence percentage was somewhat higher (but not statistically significant) for sustained smokers. Comparing quitters to sustained smokers, we found less favorable results for quitters in two out of the six associations. Among individuals with a relatively poor physical health at baseline, work ability was significantly lower for quitters. However, we found no significant differences in sickness absence and productivity loss.

\section{Methodological considerations}

This study has a number of strengths. First, few studies have determined the effect of both sustained smoking and smoking cessation on work-related outcomes (Baker et al. 2017; Halpern et al. 2001). This study is among the first to determine the effects of recent smoking cessation (Baker et al. 2017), which is more relevant from the perspective of an employer considering to implement a smoking cessation intervention in the workplace. Furthermore, we are the first to provide insight in the relation between smoking cessation and work-related outcomes in a population of older employees.

A potential limitation of this study is the measurement of smoking status. Evidence on the sensitivity and specificity of self-reported smoking status is mixed. A meta-analysis comparing self-reported smoking status with biochemical

Table 3 Longitudinal effects of smoking cessation on sickness absence, productivity loss, and work ability, stratified for physical health with sustained smokers as reference group, $N=919$

\begin{tabular}{|c|c|c|c|c|}
\hline & Univariate & Model 1 (+ demographics) & $\begin{array}{l}\text { Model } 2 \text { (+ demograph- } \\
\text { ics, job demands) }\end{array}$ & $\begin{array}{l}\text { Model } 3 \text { (+ demographics, } \\
\text { job demands, health status) }\end{array}$ \\
\hline & Coef/OR $[95 \% \mathrm{CI}]$ & Coef/OR $[95 \% \mathrm{CI}]$ & Coef/OR $[95 \% \mathrm{CI}]$ & Coef/OR $[95 \% \mathrm{CI}]$ \\
\hline \multicolumn{5}{|c|}{ Employees with relatively high physical health score at baseline } \\
\hline Sickness absence $\%{\text { (Coef })^{1}}^{1}$ & $0.06[-2.55-2.66]$ & $0.24[-2.392-0.87]$ & $0.33[-2.42-3.08]$ & $0.10[-2.67-2.87]$ \\
\hline Productivity loss $(\mathrm{OR})^{2}$ & $2.04[0.88-4.72]$ & $2.05[0.88-4.79]$ & $2.24[0.94-5.32]$ & $2.23[0.94-5.31]$ \\
\hline Work ability score $(\text { Coef })^{1}$ & $-0.09[-0.34-0.16]$ & $-0.10[-0.35-0.16]$ & $-0.10[-0.36-0.16]$ & $-0.10[-0.36-0.16]$ \\
\hline \multicolumn{5}{|c|}{ Employees with relatively low physical health score at baseline } \\
\hline Sickness absence $\%$ (Coef $)^{1}$ & $2.78[-0.91-6.47]$ & $2.82[-0.87-6.52]$ & $2.98[-0.83-6.79]$ & $2.53[-1.29-6.34]$ \\
\hline Productivity loss $(\mathrm{OR})^{2}$ & $1.40[0.77-2.56]$ & $1.43[0.78-2.61]$ & $1.30[0.70-2.41]$ & $1.26[0.66-2.39]$ \\
\hline Work ability score $(\mathrm{Coef})^{1}$ & $-0.30 *[-0.57-0.03]$ & $-0.30 *[-0.57-0.03]$ & $-0.30 *[-0.58-0.02]$ & $-0.31 *[-0.57-0.05]$ \\
\hline
\end{tabular}

$O R$ odds ratio; Coef coefficient; $C I$ confidence interval

${ }^{1}$ Results based on linear regression modelling

${ }^{2}$ Results based on logistic regression modelling 
validation found a generally high sensitivity (mean $87.5 \%$ ) and specificity (mean $89.2 \%$ ) of self-reported smoking status (Patrick et al. 1994). However, a more recent systematic review found an underestimation of smoking prevalence and varying sensitivity levels (Gorber et al. 2009). For our study, this means that we could have misclassified sustained smokers as quitters and vice versa, which might have reduced sensitivity in our sample, thereby underestimating the effects of sustained smoking and smoking cessation on work-related outcomes.

The instruments used to measure work-related outcomes were also based on self-reporting. According to literature, agreement between self-reported and recorded sickness absence days per year is relatively good (Ferrie et al. 2005). For productivity loss, few studies are available that compared self-reported with objective measures. One study found large individual differences in self-reported and objective daily work productivity reports (Finkelstein et al. 2006). Furthermore, accuracy and representativeness of self-reported work productivity depends on the recall period (Brooks et al. 2010). In the present study the recall period was 4 weeks, which is probably is good balance between accuracy and representativeness. Finally, since work productivity is influenced by multiple factors, smoking-associated work productivity might not be fully captured by our outcome variables.

\section{Interpretation of results}

In contrast to our hypothesis, we found no statistically significant differences in work-related outcomes for sustained smokers compared to non-smokers. This suggests that among older employees, sustained smokers do not have more negative work-related outcomes compared to nonsmokers. These results correspond with one study on the relation between smoking status and work ability (Tuomi et al. 2001), but are in contrast to several other studies on this relation (Kaleta et al. 2006; Tuomi et al. 1991). Furthermore, our findings are in contrast to several studies on the association between smoking status and work productivity (Berman et al. 2014; Bunn et al. 2006; Halpern et al. 2001; Sherman and Lynch 2013).

We found a higher sickness absence percentage for sustained smokers compared to non-smokers. However, this difference was not statistically significant. This is in contrast to two systematic reviews on the relation between sustained smoking and sickness absence (Troelstra et al. 2020; Weng et al. 2013), but in correspondence with several individual studies included in the systematic review which also did not find statistically significant associations between smoking and sickness absence (Boles et al. 2004; Karlsson et al. 2010; Kivimäki et al. 1997; Pai et al. 2009). A potential explanation for our results could be over-adjustment for health status. After controlling for health at baseline in model 3, the association with sickness absence changed substantially compared to model 2 but remained not statistically significant. As an additional analysis we dichotomized sickness absence and found an odds ratio of 1.10 (95\% CI 0.92-1.30) comparing sustained smoking with non-smoking. This $95 \%$ confidence interval, when interpreted as a relative risk, is lower but overlaps with the confidence intervals of risk of sickness absence for sustained smokers compared to non-smokers as reported in two recent systematic reviews (1.24-1.39 and 1.25-1.41, respectively) (Troelstra et al. 2020; Weng et al. 2013). This indicates that even though our findings are unexpected, they are within the range found by other studies.

Comparing quitters to sustained smokers, we found less favorable results for quitters in two of six associations. For work ability and quitting among individuals with a relatively poor physical health, this association was statistically significant. Several studies suggest that even though smoking cessation will increase health status and reduce mortality within a few years after cessation, it might take much longer until they are up to the level of a never smoker (Doll et al. 1994; Kenfield et al. 2008). One study found that among those who had quit smoking for less than 1 year, productivity was lower compared to sustained smokers, whereas their productivity increased and exceeded the productivity of current smokers 1-5 years after quitting smoking (Halpern et al. 2001). This study suggested that there may be a "dose-response" relationship between work productivity and years of cessation. Another study found that within 5 years of having quit smoking, work impairment was lower compared to sustained smokers; however, this study did not distinguish between the first and later years of follow-up (Baker et al. 2017). Therefore, a possible explanation for our unexpected results might be that the relatively short time our participants had quit smoking (1-5 years) is too short for the beneficial effects of smoking cessation to be manifested in this sample.

Another explanation could be that participants who were concerned about their deteriorating health status were more likely to attempt to quit smoking (Freund et al. 1992; SachsEricsson et al. 2009). Therefore, while both sustained smokers and quitters might experience a relatively poor physical health compared to non-smokers, quitters might be more likely to experience their health as having an impact on their work ability. Furthermore, quitters might have decided to quit smoking due to actual health problems, which they developed during the 6 years between T1 and T6. It has been suggested that people that are trying to quit smoking might have more unfavorable work-related outcomes compared to smokers that are not trying to quit (Baker et al. 2017). We stratified our sample based on the median physical health at the first measurement. However, changes in health status that occurred in the following years might still be of influence 
and could have encouraged a selective part of our study sample to quit smoking and might explain lower work-related outcomes in quitters compared to sustained smokers.

In this study we were unable to find support for a positive effect of implementing smoking cessation interventions among older employees in terms of work-related outcomes. However, the general body of evidence on the benefits of smoking cessation leaves no doubt towards its importance from a public health perspective and on an individual level (Jha et al. 2013; Parrott and Godfrey 2004). Employers have the opportunity to play an influential role in improving their employees' health, since they can identify, access and support their smoking employees with relative ease (Carroll et al. 2013; Fishwick et al. 2013).

\section{Conclusions}

Sustained smokers did not have higher sickness absence, productivity loss, and lower work ability compared to nonsmokers. Quitters did not have lower sickness absence and productivity loss compared to sustained smokers, but quitters might have a lower work ability compared to sustained smokers. The benefits of smoking cessation for employers might a take a longer time to develop.

\begin{abstract}
Author contributions All authors contributed to the study conception and design. SAT conducted the analyses and wrote the first draft of the manuscript. All other authors contributed to the interpretation of data, critically revised previous versions of the manuscript, and read and approved the final manuscript.
\end{abstract}

Funding No funding was received for conducting this study.

\section{Compliance with ethical standards}

Conflict of interests The authors declare that they have no competing interests.

Ethics approval The medical ethics committee of the VU University Medical Center declared that the collection of the data used in this study was not subjected to the Medical Research Involving Human Subjects Act, and therefore, ethical approval was not required.

Availability of data and material The dataset used and/or analyzed during the current study is available from the corresponding author on reasonable request.

Open Access This article is licensed under a Creative Commons Attribution 4.0 International License, which permits use, sharing, adaptation, distribution and reproduction in any medium or format, as long as you give appropriate credit to the original author(s) and the source, provide a link to the Creative Commons licence, and indicate if changes were made. The images or other third party material in this article are included in the article's Creative Commons licence, unless indicated otherwise in a credit line to the material. If material is not included in the article's Creative Commons licence and your intended use is not permitted by statutory regulation or exceeds the permitted use, you will need to obtain permission directly from the copyright holder. To view a copy of this licence, visit http://creativecommons.org/licenses/by/4.0/.

\section{References}

Airila A, Hakanen J, Punakallio A, Lusa S, Luukkonen R (2012) Is work engagement related to work ability beyond working conditions and lifestyle factors? Int Arch Occup Environ Health 85:915-925. https://doi.org/10.1007/s00420-012-0732-1

Augusto VG, Sampaio RF, Ferreira FR, Kirkwood RN, César CC (2015) Factors associated with inadequate work ability among women in the clothing industry. Work 50:275-283. https://doi. org/10.3233/wor-131801

Baker CL, Flores NM, Zou KH, Bruno M, Harrison VJ (2017) Benefits of quitting smoking on work productivity and activity impairment in the United States, the European Union and China. Int J Clin Pract 71:e12900. https://doi.org/10.1111/ijcp.12900

Bengtsson T, Nilsson A (2018) Smoking and early retirement due to chronic disability. Econ Hum Biol 29:31-41. https://doi. org/10.1016/j.ehb.2017.12.005

Berman M, Crane R, Seiber E, Munur M (2014) Estimating the cost of a smoking employee. Tob Control 23:428-433. https://doi. org/10.1136/tobaccocontrol-2012-050888

Boles M, Pelletier B, Lynch W (2004) The relationship between health risks and work productivity. J Occupat Environ Med 46:737-745. https://doi.org/10.1097/01.jom.0000131830.45744 .97

Brooks A, Hagen S, Sathyanarayanan S, Schultz A, Edington D (2010) Presenteeism: critical Issues. J Occup Environ Med 52:10551067. https://doi.org/10.1097/JOM.0b013e3181f475cc

Bunn WB, Stave GM, Downs KE, Alvir JMJ, Dirani R (2006) Effect of smoking status on productivity loss. J Occup Environ Med 48:7

Cahill K, Lancaster T (2014) Workplace interventions for smoking cessation. Cochrane Database Syst Rev. https://doi. org/10.1002/14651858.CD003440.pub4

Carroll C, Rick J, Leaviss J, Fishwick D, Booth A (2013) A qualitative evidence synthesis of employees' views of workplace smoking reduction or cessation interventions. BMC Public Health 13:1095-1095. https://doi.org/10.1186/1471-2458-13-1095

Coste J, Quinquis L, D’Almeida S, Audureau E (2014) Smoking and health-related quality of life in the general population independent relationships and large differences according to patterns and quantity of smoking and to gender. PLoS ONE 9:e91562. https:// doi.org/10.1371/journal.pone.0091562

Doll R, Peto R, Wheatley K, Gray R, Sutherland I (1994) Mortality in relation to smoking: 40 years observations on male British doctors. BMJ 309:901

Ebener M, Hasselhorn HM (2019) Validation of short measures of work ability for research and employee surveys. Int J Environ Res Public Health. https://doi.org/10.3390/ijerph16183386

Ferrie JE, Kivimäki M, Head J, Shipley MJ, Vahtera J, Marmot MG (2005) A comparison of self-reported sickness absence with absences recorded in employers registers: evidence from the Whitehall II study. Occup Environ Med 62:74

Finkelstein S, Mackell J, Tortorice D, Berndt E, Pransky G, Kyle M (2006) Objective and self-report work performance measures: a comparative analysis. Int J Prod Perform Manag 55:390-399. https://doi.org/10.1108/17410400610671426 
Fischer FM, Martinez MC (2013) Individual features, working conditions and work injuries are associated with work ability among nursing professionals. Work 45:509-517

Fishwick D et al (2013) Smoking cessation in the workplace occupational. Medicine 63:526-536. https://doi.org/10.1093/occme $\mathrm{d} / \mathrm{kqt} 107$

Fluharty M, Taylor AE, Grabski M, Munafò MR (2016) The association of cigarette smoking with depression and anxiety: a systematic review. Nicotine Tob Res 19:3-13. https://doi.org/10.1093/ ntr/ntw 140

Freund KM, D'Agostino RB, Belanger AJ, Kannel WB, Stokes IIIJ (1992) Predictors of smoking cessation: the framingham study. Am J Epidemiol 135:957-964. https://doi.org/10.1093/oxfordjour nals.aje.a116407

Goldenberg M, Danovitch I, IsHak WW (2014) Quality of life and smoking. Am J Addict 23:540-562. https://doi.org/10.111 $1 / \mathrm{j} .1521-0391.2014 .12148$

Gorber SC, Schofield-Hurwitz S, Hardt J, Levasseur G, Tremblay M (2009) The accuracy of self-reported smoking: a systematic review of the relationship between self-reported and cotinineassessed smoking status. Nicotine Tob Res 11:12-24. https://doi. org/10.1093/ntr/ntn010

Halpern MT, Shikiar R, Rentz AM, Khan ZM (2001) Impact of smoking status on workplace absenteeism and productivity. Tob Control 10:233

Husemoen LLN, Osler M, Godtfredsen NS, Prescott E (2004) Smoking and subsequent risk of early retirement due to permanent disability. Eur J Public Health 14:86-92. https://doi.org/10.1093/eurpu b/14.1.86

Ilmarinen J (2007) The work ability index (WAI). Occup Med 57:160160. https://doi.org/10.1093/occmed/kqm008

Ilmarinen J (2009) Work ability-a comprehensive concept for occupational health research and prevention. Scand J Work Environ Health. https://doi.org/10.5271/sjweh.1304

Jha P et al (2013) 21st-century hazards of smoking and benefits of cessation in the United States. N Engl J Med Overseas Ed 368:341350. https://doi.org/10.1056/NEJMsa1211128

Kaleta D, Makowiec-Dabrowska T, Jegier A (2006) Lifestyle index and work ability. Int J Occup Environ Med 19:170-177. https://doi. org/10.2478/v10001-006-0021-x

Karlsson N, Skargren E, Kristenson M (2010) Emotional support predicts more sickness absence and poorer self assessed work ability: a two-year prospective cohort study. BMC Public Health 10:648-648. https://doi.org/10.1186/1471-2458-10-648

Kenfield SA, Stampfer MJ, Rosner BA, Colditz GA (2008) Smoking and smoking cessation in relation to mortality in women. JAMA 299:2037-2047. https://doi.org/10.1001/jama.299.17.2037

Kivimäki M, Vahtera J, Thompson L, Griffiths A, Cox T, Pentti J (1997) Psychosocial factors predicting employee sickness absence during economic decline. J Appl Psychol 82:858-872. https://doi. org/10.1037/0021-9010.82.6.858

Kõks G, Fischer K, Kõks S (2018) Smoking-related general and causespecific mortality in Estonia. BMC Public Health 18:34. https:// doi.org/10.1186/s12889-017-4590-3

Lundin A, Leijon O, Vaez M, Hallgren M, Torgén M (2017) Predictive validity of the work ability index and its individual items in the general population. Scand J Public Health 45:350-356. https:// doi.org/10.1177/1403494817702759

Mohammadi S, Ghaffari M, Abdi A, Bahadori B, Mirzamohammadi E, Attarchi M (2014) Interaction of lifestyle and work ability index in blue collar workers. Glob J Health Sci 7:90-97. https://doi. org/10.5539/gjhs.v7n3p90

Nicita-Mauro V, Basile G, Maltese G, Nicita-Mauro C, Gangemi S, Caruso C (2008) Smoking, health and ageing. Immun Ageing 5:10-10. https://doi.org/10.1186/1742-4933-5-10
Østbye T, Taylor DH (2004) The effect of smoking on years of healthy life (YHL) lost among middle-aged and older Americans. Health Serv Res 39:531-552. https://doi.org/10.111 1/j.1475-6773.2004.00243.x

Pai CW, Mullin J, Payne GM, Love J, O'Connell G, Edington DW (2009) Factors associated with incidental sickness absence among employees in one health care system. Am J Health Promot 24:3748. https://doi.org/10.4278/ajhp.081117-QUAN-286

Parrott S, Godfrey C (2004) Economics of smoking cessation. BMJ 328:947. https://doi.org/10.1136/bmj.328.7445.947

Patrick DL, Cheadle A, Thompson DC, Diehr P, Koepsell T, Kinne S (1994) The validity of self-reported smoking: a review and metaanalysis. Am J Public Health 84:1086-1093

Prochaska JJ, Das S, Young-Wolff KC (2017) Smoking, mental illness, and public health. Annu Rev Public Health 38:165-185. https:// doi.org/10.1146/annurev-publhealth-031816-044618

Radkiewicz P, Widerszal-Bazyl M (2005) Psychometric properties of work ability index in the light of comparative survey study. Int Congr Ser 1280:304-309. https://doi.org/10.1016/j. ics.2005.02.089

Sachs-Ericsson N, Schmidt NB, Zvolensky MJ, Mitchell M, Collins N, Blazer DG (2009) Smoking cessation behavior in older adults by race and gender: the role of health problems and psychological distress. Nicotine Tob Res 11:433-443. https://doi.org/10.1093/ $\mathrm{ntr} / \mathrm{ntp} 002$

Sherman BW, Lynch WD (2013) The relationship between smoking and health care, workers' compensation, and productivity costs for a large employer. J Occup Environ Med 55:879-884. https:// doi.org/10.1097/JOM.0b013e31829f3129

Suwa K, Flores NM, Yoshikawa R, Goto R, Vietri J, Igarashi A (2017) Examining the association of smoking with work productivity and associated costs in Japan. J Med Econ 20:938-944. https:// doi.org/10.1080/13696998.2017.1352507

Taghizadeh N, Vonk JM, Boezen HM (2016) Lifetime smoking history and cause-specific mortality in a cohort study with 43 years of follow-up. PLoS ONE 11:e0153310. https://doi.org/10.1371/ journal.pone. 0153310

Tarro L, Llauradó E, Ulldemolins G et al (2020) Effectiveness of workplace interventions for improving absenteeism, productivity, and work ability of employees: a systematic review and meta-analysis of randomized controlled trials. Int J Environ Res Public Health 17:3

Troelstra SA, Coenen P, Boot CRL et al (2020) Smoking and sickness absence: a systematic review and meta-analysis. Scand J Work Environ Health. https://doi.org/10.5271/sjweh.3848

Tsai SP, Wen CP, Hu SC, Cheng TY, Huang SJ (2005) Workplace smoking related absenteeism and productivity costs in Taiwan. Tob Control 14(Suppl 1):i33-37. https://doi.org/10.1136/ tc. 2003.005561

Tuomi K, Eskelinen L, Toikkanen J, Jarvinen E, Ilmarinen J, Klockars M (1991) Work load and individual factors affecting work ability among aging municipal employees. Scand J Work Environ Health $1: 128-134$

Tuomi K, Huuhtanen P, Nykyri E, Ilmarinen J (2001) Promotion of work ability, the quality of work and retirement. Occup Med $51: 318-324$

Tuomi K, Ilmarinen J, Jahkola A, Katajarinne L, Tulkki A (2007) The work ability index. Occup Med. https://doi.org/10.1093/occmed/ kqm008

Van den Berg TIJ, Elders LAM, De Zwart BCH, Burdorf A (2009) The effects of work-related and individual factors on the work ability index: a systematic review. Occup Environ Med 66:211-220. https ://doi.org/10.1136/oem.2008.039883

Van den Heuvel S, Geuskens G, Bouwhuis S, Petricheva V (2016) Study on transitions in employment, ability and motivation (STREAM). Technical report TNO, Leiden 
Wacker M, Holle R, Heinrich J, Ladwig KH, Peters A, Leidl R, Menn P (2013) The association of smoking status with healthcare utilisation, productivity loss and resulting costs: results from the population-based KORA F4 study. BMC Health Serv Res 13:278. https://doi.org/10.1186/1472-6963-13-278

Ware JE, Kosinski M, Keller SD (1996) A 12-item short-form health survey: construction of scales and preliminary tests of reliability and validity. Med Care 34:220-233

Weng SF, Ali S, Leonardi-Bee J (2013) Smoking and absence from work: systematic review and meta-analysis of occupational studies. Addiction 108:307-319. https://doi.org/10.1111/add.12015

World Health Organization (2018) Tobacco Fact sheet. https://www. who.int/mediacentre/factsheets/fs339/en/. (Accessed 5 Apr 2018)
Ybema J et al (2014) Study on transitions in employment, ability and motivation (STREAM): the design of a four-year longitudinal cohort study among 15,118 persons aged 45-64 years. Br J Med Med Res 4:1383-1399

Publisher's Note Springer Nature remains neutral with regard to jurisdictional claims in published maps and institutional affiliations. 